\title{
Dihydroisotanshinone I combined with radiation inhibits the migration ability of prostate cancer cells through DNA damage and CCL2 pathway
}

I-Yun Lee ${ }^{1 \dagger}$, Yin-Yin Lin ${ }^{1 \dagger}$, Yao-Hsu Yang ${ }^{1}$, Yu-Shin Lin ${ }^{3}$, Chun-Liang Lin ${ }^{4,5}$, Wei-Yu Lin ${ }^{6,7}$, Yu-Ching Cheng ${ }^{1}$, Li-Hsin Shu ${ }^{1}$ and Ching-Yuan $\mathrm{Wu}^{1,2^{*}}$

\begin{abstract}
Background: Radiotherapy plays an important role in the treatment of prostate cancer. Despite that sophisticated techniques of radiotherapy and radiation combined with chemotherapy were applied to the patients, some tumors may recur. Therefore, the study investigated the effect of dihydroisotanshinone I (DT) and the combination treatment of $5 \mu \mathrm{M}$ DT and 5Gy irradiation (IR) against the migration ability of prostate cancer cells.

Methods: DT and the combination treatment were studied for its biological activity against migration ability of prostate cancer cells with transwell migration assay. Subsequently, we tried to explore the underlying mechanism with ELISA, flow cytometry and Western's blotting assay.

Results: The results showed that DT and the combination treatment substantially inhibited the migration ability of prostate cancer cells. DT and the combined treatment can decrease the ability of macrophages to recruit prostate cancer cells. Mechanistically, DT and the combination treatment reduced the secretion of chemokine (C-C Motif) Ligand 2 (CCL2) from prostate cancer cells. We also found that DT treatment induced the cell cycle of prostate cancer cells entering $\mathrm{S}$ phase and increased the protein expression of DNA damage response proteins ( $r \mathrm{H} 2 \mathrm{AX}$ and phosphorylated ataxia telangiectasia-mutated [ATM]) in DU145 cells and PC-3 cells.

Conclusions: DT displays radiosensitization and antimigration effects in prostate cancer cells by inducing DNA damage and inhibiting CCL2 secretion. We suggest that DT can be used as a novel antimetastatic cancer drug or radiosensitizer in the armamentarium of prostate cancer management.
\end{abstract}

Keywords: Dihydroisotanshinone I, Radiosensitive, Prostate cancer, DNA damage, CCL2

\section{Background}

Radiotherapy is an effective form of local cancer treatment because it induces the DNA damage response (DDR) [1]. However, a fraction of tumors recur after such treatment, usually in more aggressive and metastatic forms [2]. Sensors inside cells can recognize DNA damage and start the DDR process, which induces cell cycle arrest to allow the

\footnotetext{
* Correspondence: smbepigwu77@gmail.com

${ }^{\dagger}$ Equal contributors

'Department of Chinese Medicine, Chiayi Chang Gung Memorial Hospital, No.6, W. Sec., Jiapu Rd., Puzi City, Chiayi County 613, Taiwan, Republic of China

${ }^{2}$ School of Chinese medicine, College of Medicine, Chang Gung University,

Tao-Yuan, Taiwan

Full list of author information is available at the end of the article
}

damaged DNA to be repaired. Among the different types of DNA damage events, DNA double-strand breaks (DDBs) are the most lethal. During DDBs, ATM (previously known as ataxia-telangiectasia mutated) is phosphorylated and activated, serving as a pivotal regulator for the execution of DDR in the maintenance of genomic stability. Another protein, $\mathrm{H} 2 \mathrm{AX}$, acts as an important platform for recruiting DDR proteins. Activated ATM then phosphorylates histone H2AX at S139 (known as $r \mathrm{H} 2 \mathrm{AX}$ ), which recruits a mediator of DNA damage, checking protein 1 (MDC1), to the sites of DNA breaks, which in turn recruits downstream repair proteins to DNA damage foci for repair [3-5]. During DDBs, the $\mathrm{S}$ 
phase can be delayed. Notably, these DDR proteins can be crucial in cancer treatment with chemotherapy agents and radiotherapy. Despite the sophisticated radiation techniques that have been developed, as well as the combination of radiation with chemotherapy, some tumors do recur. Thus, a method that improves the local control of primary or metastasized tumors with a combination of radiotherapy and radiosensitizer may be beneficial for patients with cancer.

Tumor-associated macrophages are derived from peripheral blood monocytes that are recruited into the tumor and potentiate the seeding and establishment of metastatic cells [6]. C-C motif chemokine ligand 2 (CCL2), also known as monocyte chemoattractant protein-1, was first identified by its ability to attract monocytes in vitro $[7,8]$. CCL2 recruits prostate cancer epithelial cells to the bone microenvironment and regulates their rate of proliferation $[9,10]$. Dihydroisotanshinone I (DT) (Fig. 1a), a substance extracted from the dried root of Salvia miltiorrhiza Bunge, contains abietane-type diterpene quinone. In a previous study [11], tanshinone IIA inhibited the metastasis of hepatocellular carcinoma and was identified as a potential means of increasing survival rates. In our previous study, we noted that DT substantially inhibited the migratory ability of prostate cancer cells in both a macrophageconditioned medium and a macrophage/prostate cancer coculture medium [12]. However, the effect of DT combined with radiotherapy on prostate cancer cells and the underlying mechanism remain unclear. In this study, we investigated the effect of DT in combination with ionizing radiation (IR) on the migration of prostate cancer cells in a macrophage medium. We also observed the exact mechanism for combining DT with radiation therapy.

\section{Methods}

\section{Cell culture and treatment}

The human prostate cancer cell lines (DU145 cells and PC3 cells), human acute monocytic leukaemia cell line (THP1 cells), IMR-9 cells (human normal lung fibroblast) were obtained from the American Type Culture Collection. The DU145 cells and PC-3 cells were cultured in Dulbecco's Modified Eagle's medium (DMEM) (Invitrogen Corp., Carlsbad, CA), supplemented with $10 \%$ FBS at $37{ }^{\circ} \mathrm{C}$ and $5 \% \mathrm{CO}_{2}$. The THP1 cells were cultured in RPMI-1640 medium (RPMI) (Invitrogen Corp., Carlsbad, CA), supplemented with $10 \%$ fetal bovine serum (FBS) at $37{ }^{\circ} \mathrm{C}$ and $5 \%$ $\mathrm{CO}_{2}$. IMR-90 cells were cultured in Minimum essential medium Eagle (Invitrogen Corp., Carlsbad, CA), supplemented with $10 \%$ fetal bovine serum (FBS) at $37{ }^{\circ} \mathrm{C}$ and $5 \%$ CO2. Recombinant Human CCL2 was obtained from Peprotech. Dihydroisotanshinone I (DT) was obtained from ChemFaces Natural Products Co., Ltd., China (Catalog number: CFN-90162, the purity of dihydroisotanshinone is $98 \%$ and its solubility in DMSO is $>5 \mathrm{mg} / \mathrm{mL}$ ). Human prostate cancer cells and macrophages were cultured to $60-70 \%$ confluence prior to treatment. Medium was then replaced with fresh medium containing dihydroisotanshinone in DMSO (dimethyl sulfoxide) at the indicated concentrations. Cells treated with DMSO alone were used as untreated controls.

\section{Cell migration assay}

Cell migration assays were performed as described previously [13]. For the migration of human prostate cancer cells in monoculture, the indicated cell lines (DU145 cells, PC-3 cells, or IMR-90 cells $)\left(1 \times 10^{5}\right.$ cells/well) were plated in the upper chambers of Transwell plates with 8 - $\mu \mathrm{m}$ pore polycarbonate membrane inserts in a medium without fetal bovine serum (FBS). A medium with FBS was plated in the lower chambers. After treatment or no treatment with dimethyl sulfoxide (DMSO) and with the indicated treatment for 16-24 h, the cells that had migrated to the bottom were fixed and stained using $1 \%$ toluidine blue. The numbers of cells were averaged after six randomly selected fields were counted. For the prostate cancer recruitment assay, THP- 1 cells $\left(1 \times 10^{5}\right.$ cells/well $)$ were cultured for $24 \mathrm{~h}$. The THP- 1 cell medium was then collected and plated in the lower chambers. After treatment or no treatment with DMSO and with the indicated treatment for $24 \mathrm{~h}$, the human prostate cancer cells (DU145 cells or PC-3 cells) $\left(1 \times 10^{5}\right.$ cells/well $)$ were plated in the upper chambers in the medium without FBS. After incubation for 16-24 $\mathrm{h}$, the cells that had migrated into the bottom were fixed and stained using $1 \%$ toluidine blue, and the numbers were averaged after six randomly selected fields were counted. Each sample was assayed in triplicate, and each experiment was repeated at least twice.

\section{Enzyme-linked immunosorbent assay}

Enzyme-linked immunosorbent assays (ELISAs) were performed as described previously [14]. The medium was collected from a monoculture of prostate cancer cells with or without DMSO treatment, the indicated concentration of DT, or the indicated dose of IR for $24 \mathrm{~h}$. Human CCL2 or human interleukin 8 (IL-8) in medium were detected with human CCL2 ELISA kits (eBioscience, catalog number: 887399) or human IL-8 ELISA kits (eBioscience, catalog number: 88-8086) according to the manufacturer's instructions.

\section{Western blot analysis}

Western blot analyses were performed as described previously [15]. Cellular extracts of the human prostate cancer cell line (DU145 cells and PC-3 cells) that had been treated with DMSO or $10 \mu \mathrm{M}$ of DT for 0 or $6 \mathrm{~h}$ were prepared according to the manufacturer's instructions. Equal amounts of protein were fractionated via $6 \%$ or $12 \%$ SDS-PAGE and transferred to polyvinylidene difluoride (PVDF) membranes. The membranes were then blocked with 5\% nonfat dried milk for $30 \mathrm{~min}$ and incubated in primary antibody for $3 \mathrm{~h}$ at room 
<smiles>Cc1cccc2c3c(ccc12)C(=O)c1c(c1=O)OCC3C</smiles>
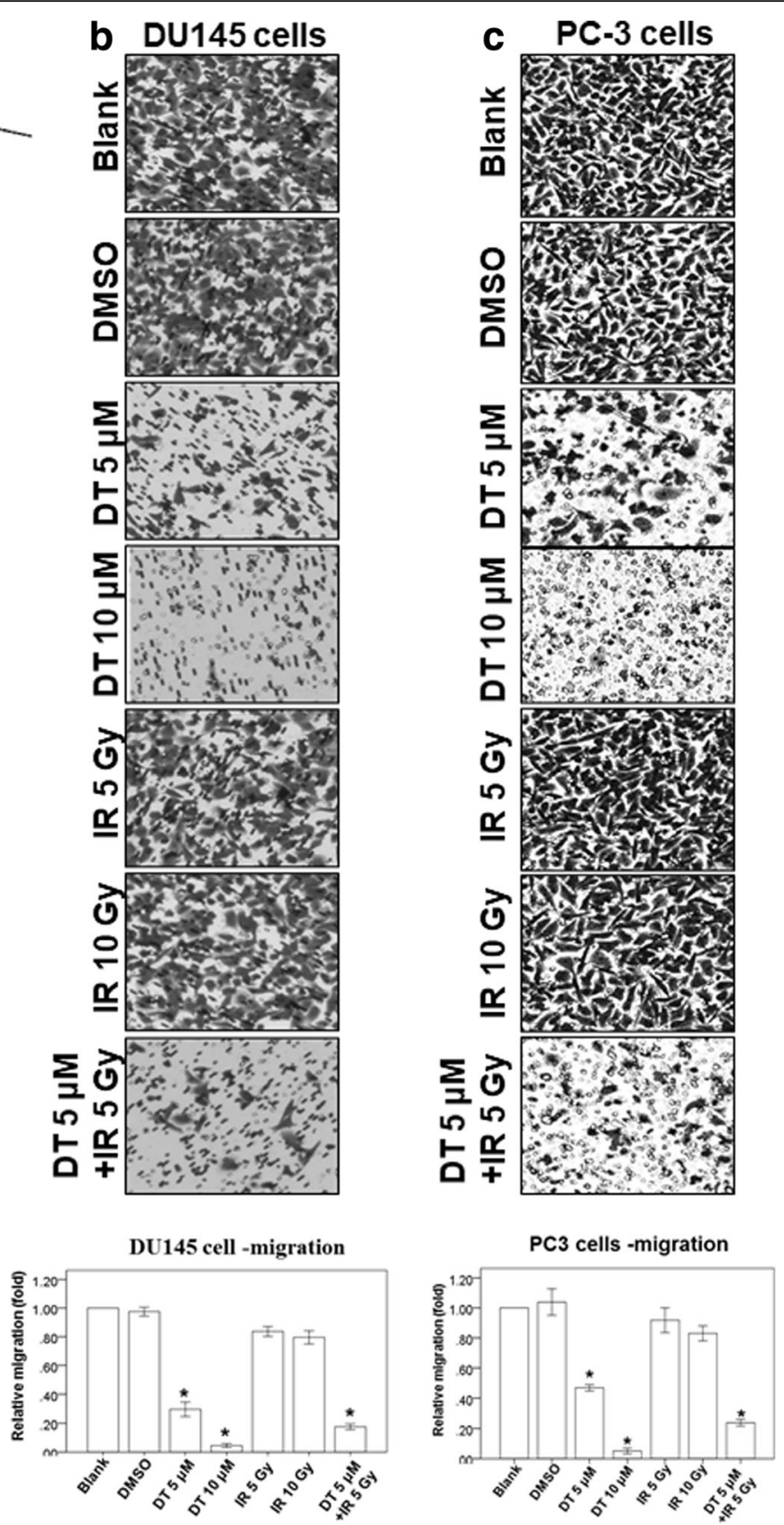

Fig. 1 DT blocks different human prostate cancer cells migration on in vitro Transwell migration assay. a The structure of dihydroisotanshinone I (DT). b, c, The migration ability of DU145 cells (b) and PC-3 cells (c) were measured with the transwell migration assay. After treated with indicated drugs for $24 \mathrm{~h}$, the photographs $(\times 100)$ were taken and the migratory cells were measured using AlphaEase ${ }^{\oplus} \mathrm{FC}$ StandAlone Software. Numbers of the migratory DU145 cells and PC-3 cells in each group were normalized to the control. The results were from three independent experiments. (Error bar $=$ mean \pm S.E.M. Asterisks $(*)$ mark samples significantly different from blank group with $p<0.05$ )

temperature. The primary antibodies used were anti-H2AX antibody (Cell Signaling, ratio: 1:1000), antiphosphorylated (S139)-H2AX antibody (Cell Signaling, ratio: 1:1000), antiATM antibody (Cell Signaling, ratio: 1:1000), antiphosphorylated (S1981)-ATM antibody (Rockland, ratio:1:2000), and anti- $\alpha$-tubulin antibody (Santa Cruz, IB: 1:10,000). The primary and secondary antibodies were diluted with $1 \%$ nonfat dried milk in 0.1\% tris-buffered saline with Tween 20 (TBST). Blots were washed with $0.1 \%$ TBST and incubated in horseradish peroxidase-conjugated secondary antimouse or antirabbit antibodies (Santa Cruz, ratio: 1:5000) for $1 \mathrm{~h}$ at room temperature. After washing with 1X TBST again, protein signals were detected by chemiluminescence with the SuperSignal Substrate (Pierce, Number: 34,087). 


\section{Cell cycle assay}

DU145 cells or PC-3 cells $\left(1 \times 10^{6}\right.$ cells $)$ were seeded in a $100-\mathrm{mm}$ plate and cultured overnight before treatment. The cells were then treated with $10 \mu \mathrm{M}$ of DT for $0-6 \mathrm{~h}$. After incubation, the cells were analyzed using flow cytometry with propidium iodide (PI) staining to determine the distribution of the G0/G1, G2/M, and S phases of the cell cycle. Briefly, the medium was removed and harvested after washing with phosphate-buffered saline (PBS). The supernatant was removed by centrifugation. Cell pellets were washed with PBS and fixed in $75 \%$ ethanol overnight at $-20{ }^{\circ} \mathrm{C}$. The next day, the treated cells were washed with cold PBS and stained with PI solution $(50 \mu \mathrm{g} / \mathrm{mL}$ PI [Sigma-Aldrich] and $0.5 \mu \mathrm{g} / \mathrm{mL}$ ribonuclease [Sigma-Aldrich] in PBS) in a $37{ }^{\circ} \mathrm{C}$ water bath for $15 \mathrm{~min}$. The cell cycle stages were measured by flow cytometry.

\section{Statistical analyses}

All values were the means \pm standard error of mean (SEM) of the replicate samples ( $n=3$ to 6 , depending on the experiment) and experiments were repeated by a minimum of three times. Differences between two groups were assessed using the unpaired two-tailed Student's $t$-test or by ANOVA if more than two groups were analyzed. The Tukey test was used as a post-hoc test in ANOVA for testing the significance of pairwise group comparisons. $P$ values $<0.05$ were considered statistically significant in all comparisons. SPSS version 13.0 for windows (LEAD technologies, Inc.) was used for all calculations.

\section{Results}

DT and the combination treatment can block cell motility in different human prostate cancer cells

To study the effect of DT on the migration ability of prostate cancer cells, we used two prostate cancer cell lines (PC-3 and DU145) to study the function of DT, IR, and the combined therapy with $5 \mu \mathrm{M}$ DT and 5 Gy IR in the migration assay (Fig. 1b, c). The results showed that 5-10 $\mu \mathrm{M}$ DT considerably inhibited the migration ability of prostate cancer cells in a dose-dependent manner. We also used 5-10 Gy IR to compare the effects of DT on migration. Our results showed that neither 5 nor 10 Gy IR were able to inhibit the migration ability of prostate cancer cells, whereas $10 \mu \mathrm{M}$ DT was able to do so. Combination treatment with $5 \mu \mathrm{M}$ DT and 5 Gy IR substantially inhibited the migration ability of prostate cancer cell as $10 \mu \mathrm{M}$ DT did. These data suggest that DT and the combined therapy can inhibit the migration of prostate cancer cells in an effective manner.

\section{Effects of DT and the combined therapy on prostate cancer cell migration in the THP-1 cell medium} Previous studies have shown that macrophages promote tumor invasion and metastasis and that the motility of human prostate cancer cells is inhibited by DT. Therefore, we investigated the effect of DT and the combined therapy on the ability of macrophages to promote tumor migration. Because THP-1 cells are extensively used to study monocyte/macrophage functions, mechanisms, signaling pathways, and drug activities [16, 17], we used THP-1 cells as our model (Fig. 2a). In the control group, DU145 cells and PC-3 cells were recruited by the conditioned medium. This demonstrated that THP-1 cell medium can promote the migration ability of prostate cancer cells. However, 5$10 \mu \mathrm{M}$ DT markedly inhibited the migration of prostate cancer cells in a dose-dependent manner in the THP-1 cell medium (Fig. 2b, c). Moreover, 5 and 10 Gy IR alone did not inhibit the migration ability of DU145 cells and PC-3 cells. However, combined treatment ( $5 \mu \mathrm{M}$ DT plus 5 Gy IR) was able to inhibit the migration ability of prostate cancer cells. These data suggested that DT or combined treatment may diminish the ability of macrophages to recruit prostate cancer cells.

\section{DT and combined therapy inhibit the secretion of CCL2 by prostate cancer cells}

Our results indicated that DT inhibits the motility of prostate cancer cells, even in the THP-1 cell medium. In previous studies, increased CCL2 expression in prostate cancer cells encouraged metastasis through macrophage recruitment [18-20]. In another study, IL-8 was demonstrated to be an important molecule for androgen-independent prostate cancer growth and progression [21]. We subsequently used ELISA to examine the effects of different treatments on the secretion of IL- 8 or CCL 2 by prostate cancer cells. After conducting the indicated treatment for $24 \mathrm{~h}$, we found that IL-8 secretion was not inhibited (Fig. 3a, c). However, DT and combined treatment with IR ( $5 \mu \mathrm{M}$ DT plus 5 Gy IR) considerably inhibited the secretion of CCL2 by prostate cancer cells (Fig. 3b, d). To validate the critical role of CCL2 in controlling the migration ability of DT-treated prostate cancer cells, we investigated the effects of DT or combined treatment with IR ( $5 \mu \mathrm{M}$ DT plus 5 Gy IR) and with or without CCL2 on the migration ability of prostate cancer cells. After adding $5 \mathrm{pg} / \mathrm{mL}$ of CCL2 to the conditioned medium, we observed that CCL2 partially rescued the migration ability of DT- or combination-treated PC-3 cells (relative migration: from 30 to $40 \%$ to $60 \%$ ) (Fig. 3f). Our results suggest that CCL2 is among the cytokines that control the migration ability of DT- or combination-treated prostate cancer cells, and that DT and combined treatment inhibit the migration of prostate cancer cells through their effects on CCL2. In our previous study, we found that the proliferation of IMR90 cells (normal human lung fibroblasts) was mildly inhibited by $5 \mu \mathrm{M}$ DT treatment for $24 \mathrm{~h}$ [22]. In addition, we discovered that $5 \mu \mathrm{M}$ DT inhibits the migration ability of IMR-90 cells (Fig. 3e). The migration ability of IMR-90 cells was mildly inhibited by 5 Gy IR. In the present study, 

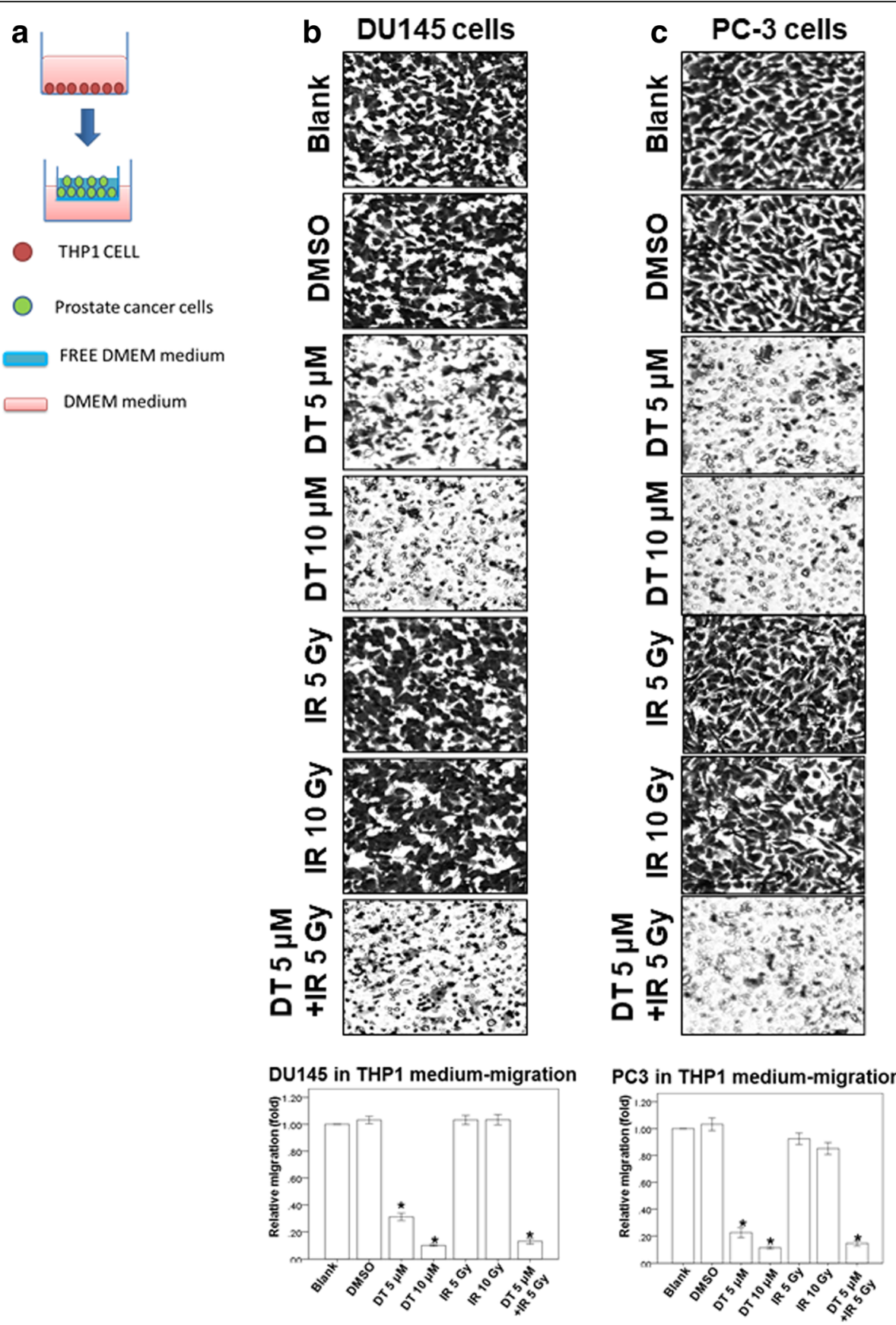

Fig. 2 The effect of DT on prostate cancer cell migration in the THP1 cell medium. The migration ability of human prostate cancers in the THP1 cells medium were measured with the transwell migration assay. a THP1 cells were cultured for $24 \mathrm{~h}$. Then the condition medium were collected and placed in the lower chamber. b, c The DU145 cells (b) and PC-3 cells (c) were then placed on the upper chamber for the migration assay. After incubation for $24 \mathrm{~h}$, the photographs $(\times 100)$ were taken and the migratory cells were measured using AlphaEase ${ }^{\oplus} \mathrm{FC}$ StandAlone Software. Numbers of the migratory DU145 cells and PC-3 cells in each group were normalized to the control. The results were from three independent experiments. (Error bars $=$ mean \pm S.E.M. Asterisks $\left(^{*}\right)$ mark samples significantly different from blank group with $p<0.05$ )

combination treatment with $5 \mu \mathrm{M}$ DT and 5 Gy IR was also able to inhibit the migration ability of prostate cancer cells. These data suggest that DT and the combined therapy can inhibit the migration ability of both prostate cancer cells and normal human lung fibroblasts.
Effects of DT on cell cycle progression of prostate cancer cells in vitro

Because DT demonstrated potential antimigration effects on prostate cancer cells, we further investigated the mechanism of DT on prostate cancer cells. First, we determined 

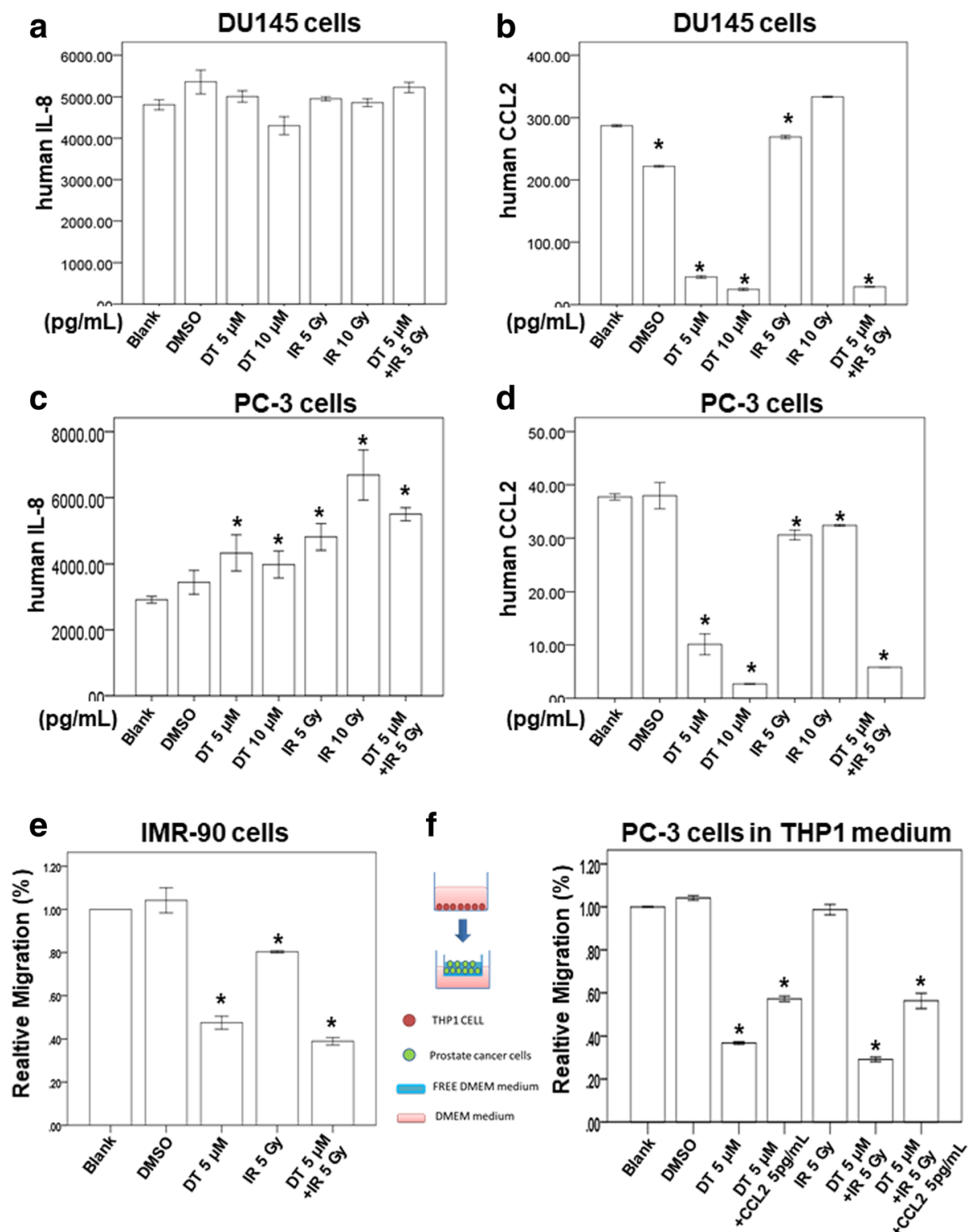

Fig. 3 Effects of DT on the protein secretion of IL8 or CCL2 from prostate cancer cells and on human normal fibroblasts migration in the THP1 cell medium. The condition medium of coculture with DU145 cell or PC-3 cells were collected from untreated cells, cells treated with DMSO or indicated treatment for $24 \mathrm{~h}$. The secretion of human IL8 was measured with ELISA kits $(\mathbf{a}, \mathbf{c})$. The secretion of human CCL2 was measured with ELISA kits (b, d). e The migration ability of IMR-90 cells were measured with the transwell migration assay. After treated with indicated drugs for $24 \mathrm{~h}$, the photographs ( $x$ 100) were taken and the migratory cells were measured using AlphaEase ${ }^{\oplus}$ FC StandAlone Software. Numbers of the migratory IMR-90 cells in each group were normalized to the control. $\mathbf{f}$ The migration ability of human prostate cancers in the macrophages medium were measured by the transwell migration assay. THP1 cells were treated with DMSO or DT for $24 \mathrm{~h}$. Then the conditioned medium was collected and placed in the lower chamber. In the group of DT+ $5 \mathrm{pg} / \mathrm{mL}$ CCL2, $5 \mathrm{pg} / \mathrm{mL}$ CCL2 was added into the condition medium of this group. Then, PC-3 cells were then placed on the upper chamber for the migration assay. After incubation for $24 \mathrm{~h}$, the photographs $(\times 100)$ were taken and the migratory cells were measured using AlphaEase ${ }^{\oplus} \mathrm{FC}$ StandAlone Software. The quantification of the indicated migratory cells numbers in each group were normalized to the control. All the results are representative of at least three independent experiments. (Error bars $=$ mean \pm S.E.M. Asterisks $\left.{ }^{*}\right)$ mark samples significantly different from blank group with $p<0.05$ )

the effect of DT on the cell cycle progression of prostate cancer cells. Compared with the control cells, the S-phase proportion of cells treated with $10 \mu \mathrm{M}$ DT increased from $30 \%$ to $40-50 \%$ in $6 \mathrm{~h}$ (Fig. 4). The results showed that DT treatments were able to prolong or arrest the $\mathrm{S}$ phase of the prostate cancer cell cycle.

\section{DT regulates DDR proteins in prostate cancer cells}

During DDBs, ATM is autophosphorylated at serine 1981 and phosphorylates $\mathrm{H} 2 \mathrm{AX}$ at serine 139 , which then recruits downstream repair proteins to DNA damage foci for repair. In this stage, the $\mathrm{S}$ phase can be delayed. Several cellular factors that are directly phosphorylated by ATM 


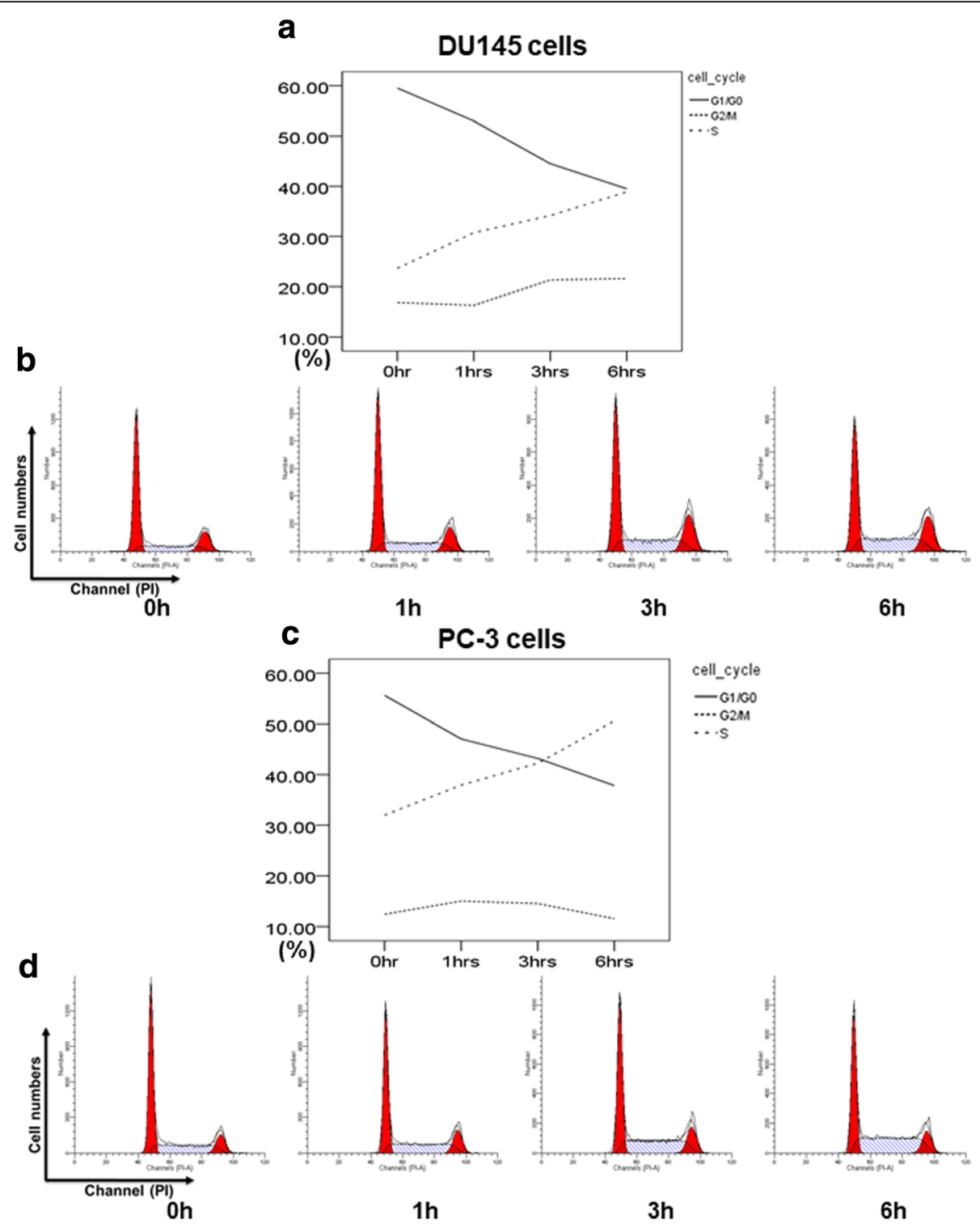

Fig. 4 Effects of DT on human prostate cancer cell cycle. DU145 cells or PC-3 cells were treated with $10 \mu \mathrm{M}$ of DT for 0, 1, 3, $6 \mathrm{~h}$ and then subjected to flow cytometry with PI staining. The cell cycle phase distribution of DU145 cells (a) or PC-3 cells (c) after treatment with DT were measured in the indicated hours. The representative histograms between PI intensity and cell numbers of DU145 cells (b) or PC-3 cells (d) were measured by flow cytometry

contribute to the S-phase checkpoint. Considering how the previous data showed that DT may prolong the S phase of the cell cycle in prostate cancer cells after $6 \mathrm{~h}$, we used a western blot assay to investigate its effect on these DNA damage proteins, phosphorylated (S1981)-ATM (p-ATM) and H2AX, in DU145 cells and PC-3 cells. We found that $10 \mu \mathrm{M}$ DT induced the protein expression of $\mathrm{H} 2 \mathrm{AX}$ and p-ATM in DU145 cells (Fig. 5a) or PC-3 cells (Fig. 5b) within $6 \mathrm{~h}$. These data suggested DT has the potential to induce DDR in prostate cancer cells.

\section{Discussion}

In previous studies, various members of the tanshinone family were demonstrated to be capable of inhibiting the growth of several types of cancer cells, including prostate cancer cells [23-25]. Moreover, tanshinone IIA can suppress the migration ability of osteosarcoma MG-63 cells and gastric cancer AGS cells [26, 27]. Another recent study showed that 15,16-dihydrotanshinone I has a structure similar to that of DT and induces endoplasmic reticulum stress in prostate carcinoma cells (DU145 cells) [28]. 

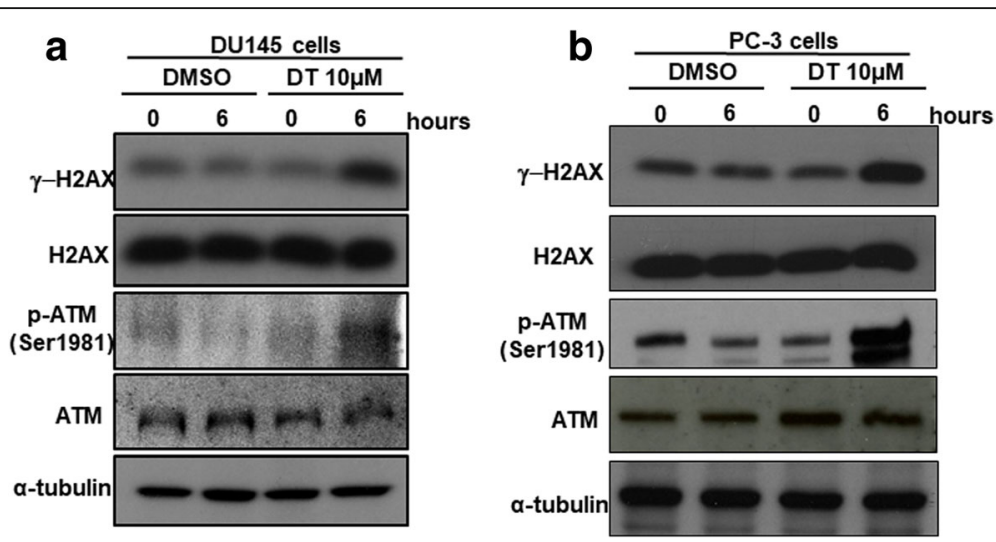

Fig. 5 DT inhibits the protein expression of DNA damage response proteins in prostate cancer cells. Total cell extracts of DU145 cells (a) or PC-3 cell (b) were harvested from untreated cells and cells treated with DMSO or DT for $0,6 \mathrm{~h}$. The protein was immunoblotted with polyclonal antibodies specific for DNA damage response proteins ( $\mathrm{y}-\mathrm{H} 2 \mathrm{AX}$ and phosphorylated-ATM). a-tubulin was used as an internal loading control

Tanshinone IIA and DT possess an ortho-quinone and an intact ring D, respectively, suggesting that the structure of tanshinones may influence the ways in which they inhibit migration ability in tumors. In our previous study, we also found that DT substantially inhibited the migratory ability of prostate cancer cells in both a macrophage-conditioned medium and macrophage/prostate cancer coculture medium [12]. In this study, we discovered that the combination treatment with $5 \mu \mathrm{M}$ DT and 5 Gy IR more strongly inhibited the migration ability of prostate cancer cells compared with $5 \mu \mathrm{M}$ DT (Figs. 1 and 2). These results suggest that DT cooperates with radiation therapy and demonstrate the effectiveness of the combined therapy in inhibiting the migration of prostate cancer cells.

CCL2 regulates macrophage differentiation, growth, and chemotaxis [29]. Furthermore, CCL2 was previously shown to inhibit the generation of tumor-reactive T cells [30]. Tanshinone IIA was found to have considerable growthinhibiting effects on U-937 cells through the induction of apoptosis by downregulation of CCL2 expression [25]. In our previous studies, DT reduced the secretion of CCL2 by both lung cancer cells and prostate cancer cells [12, 22], yet the effect of the combined therapy on CCL2 secretion by prostate cancer cells is unclear. In the present study, we discovered that IR 5 Gy mildly decreased CCL2 secretion by both PC-3 and DU145 cells. Moreover, the combination treatment inhibited CCL2 secretion by prostate cancer cells more strongly than $5 \mu \mathrm{M}$ DT did (Fig. $3 \mathrm{~b}$ and d). These results suggest that DT cooperates with radiation therapy to affect CCL2 secretion. The previous report showed that tanshinone IIA inhibited cyclic strain-induced IL-8 expression by the induction of heme oxygenase (HO-1) in endothelial cells [31]. Tanshinone I also reduced the transcriptional activity of IL-8 [32]. In our results, DT did not decrease the secretion of IL- 8 by either PC-3 or DU145 cells. In a previous study, fluorouracil, which interrupts the action of this enzyme and blocks synthesis of the pyrimidine thymidine, increased the levels of IL-8 secreted from PC-3 cells [33]. Notably, increased IL-8 expression was also observed after treatment with DT only, IR only, or combined therapy in PC-3 cells (Fig. 3c). These results suggest that the mechanism of DT on PC-3 cells may occur at the DNA level. By contrast, a previous study showed that the structural difference between several tanshinones at the $\mathrm{C}-15$ position of the furan ring resulted in differential inhibition of CYP3A (cytochrome P450 3A) activity [34]. The positioning of the furan ring in DT and tanshinone IIA might have caused this difference. The underlying mechanism will be investigated in our future research.

Among the various types of DNA damage, the most deleterious is DNA DDBs. Double-strand breaks can be generated using exogenous sources, including IR or chemotherapeutic agents. During DDBs, ATM is phosphorylated and then phosphorylates histone H2AX at S139 (known as $\gamma \mathrm{H} 2 \mathrm{AX}$ ). If they remain unrepaired, DDBs may induce cell death and apoptosis [35]. Numerous chemotherapeutic agents and types of radiotherapy exert cytotoxic effects by inducing DNA DDBs. According to previous studies, tanshinone IIA can bind to the DNA minor groove [36] and significantly sensitize oral squamous cell carcinoma to radiation through the autophagy pathway [37]. In one report, 5-20 $\mu \mathrm{M}$ tanshinone IIA combined with IR 6Gy was able to induce $\gamma \mathrm{H} 2 \mathrm{AX}$ expression. However, the effect of tanshinone monotherapy on the DNA damage pathway is still unclear. This is the first study to demonstrate that $10 \mu \mathrm{M}$ DT increased the $\mathrm{S}$ phase proportion of the cell cycle and phosphorylated ATM and $\gamma \mathrm{H} 2 \mathrm{AX}$ expression in prostate cancer cells. The results suggest that DT can induce DNA DSBs and increase the effect of IR.

In one meta-analysis of patients with locally advanced prostate cancer, optimal oncological outcomes were obtained through radical prostatectomy with adjuvant radiotherapy or radiotherapy with adjuvant hormonal therapy [38]. These results suggest that radiotherapy is a vital 
treatment for locally advanced prostate cancer. However, radiotherapy can increase the risk of urinary incontinence, bladder neck contracture, and urethral stricture [39, 40], and can cause capillary destruction with reduced vascularity and tissue fibrosis [39]. To improve outcomes, in several countries radiotherapy is often combined with complementary and alternative medicine [41-43]. Notably, tanshinone IIA not only sensitizes oral squamous cell carcinoma to radiation through the autophagy pathway [37], but also has a protective effect against radiation-induced ototoxicity in HEI-OC1 cells, a mouse auditory cell line [44]. Sodium tanshinone IIA sulfonate has also been shown to prevent radiation-induced toxicity in cardiomyocytes [45]. These reports suggest that tanshinones have different effects on radiation therapy in different cell lines. However, the effects and mechanisms of these combined therapies on the immune system are still unclear. Our results first demonstrated that combined treatment ( $5 \mu \mathrm{M}$ DT with 5 Gy IR) was able to diminish migration of prostate cancer cells in a more effective manner than did the larger dose of IR (10 Gy). The combination treatment reduced CCL2 in prostate cancer cells. In addition, the combined treatment decreased the ability of macrophages to recruit prostate cancer cells. In our previous study, we also discovered that DT inhibited the secretion of CCL2 by the cultured medium of macrophages, including THP-1 cells and RAW 264.7 cells [12]. These results suggest that macrophages and cytokines, like CCL2, may regulate the effect of combined treatment on prostate cancer.

\section{Conclusions}

In conclusion, DT displays radiosensitization and antimigration effects in prostate cancer cells by inducing DNA damage and inhibiting CCL2 secretion. We suggest that DT can be used as a novel antimetastatic cancer drug or radiosensitizer in the armamentarium of prostate cancer management.

\section{Abbreviations}

ATM: Ataxia telangiectasia-mutated; CCL2: Chemokine C-C Motif Ligand 2; DDBs: DNA double-strand breaks; DDR: DNA damage response; DMEM: Dulbecco's Modified Eagle's medium; DMSO: Dimethyl sulfoxide; DT: Dihydroisotanshinone l; ELISA: Enzyme-linked immunosorbent assay; FBS: Fetal bovine serum; MDC1: Mediator of DNA damage checking protein 1; PVDF: Polyvinylidene difluoride; SDS-PAGE: Sodium dodecyl sulfate polyacrylamide gel electrophoresis; SEM: Standard error of mean; TBST: Tris-Buffered Saline Tween-20

\section{Acknowledgements}

Not applicable.

\section{Funding}

This work was supported by grant CMRPG6C0262, CMRPG6D0343, CMRPG6F0011, CMRPG6F0661, CMRPG6E0091, CMRPG6F0551 and CMRPG6F0171 from Chang Gung Memorial Hospital, and MOST 105-2320-B182-006-MY3, NSC 101-2320-B-182A-005 and NSC 102-2320-B-182A-007 from the Ministry of Science and Technology, Taiwan.

Availability of data and materials

All data and materials are contained and described within the manuscript.

\section{Authors' contributions}

IYL contributed to the conception and design of the entire study. IYL and YYL carried out most of the experiments, contributed to the data interpretation and wrote the initial draft of the manuscript. YHY contributed to the experimental design. YSL and WYL contributed to data interpretation and the final editing of the manuscript. YCC, MCL and LHS contributed to Western's blotting assay, migration assay and cell cycle assay. KDL participated in the project design and to the data interpretation. CYW provided grant support, funding and the final editing of the manuscript. All authors read and approved the final manuscript.

Ethics approval and consent to participate

Not applicable.

\section{Consent for publication}

Not applicable.

\section{Competing interests}

The authors declare that they have no competing interests.

\section{Publisher's Note}

Springer Nature remains neutral with regard to jurisdictional claims in published maps and institutional affiliations.

\section{Author details}

'Department of Chinese Medicine, Chiayi Chang Gung Memorial Hospital, No.6, W. Sec., Jiapu Rd., Puzi City, Chiayi County 613, Taiwan, Republic of China. ${ }^{2}$ School of Chinese medicine, College of Medicine, Chang Gung University, Tao-Yuan, Taiwan. ${ }^{3}$ Department of Pharmacy, Chiayi Chang Gung Memorial Hospital, Chiayi, Taiwan. ${ }^{4}$ Departments of Nephrology, Chiayi Chang Gung Memorial Hospital, Chiayi, Taiwan. ${ }^{5}$ Kidney and Diabetic Complications Research Team (KDCRT), Chiayi Chang Gung Memorial Hospital, Chiayi, Taiwan.

${ }^{6}$ Department of Urology, Chang Gung Memorial Hospital at Chiayi, Puzi City, Taiwan. ${ }^{7}$ Chang Gung University of Science and Technology, Chia-Yi, Taiwan.

Received: 22 March 2017 Accepted: 25 January 2018

Published online: 31 January 2018

\section{References}

1. Bernier J, Hall EJ, Giaccia A. Radiation oncology: a century of achievements. Nat Rev Cancer. 2004:4:737-47.

2. Suit HD. Local control and patient survival. Int J Radiat Oncol Biol Phys. 1992;23:653-60.

3. Huen MS, Sy SM, Chen J. BRCA1 and its toolbox for the maintenance of genome integrity. Nat Rev Mol Cell Biol. 2010;11:138-48.

4. Panier S, Durocher D. Regulatory ubiquitylation in response to DNA doublestrand breaks. DNA Repair (Amst). 2009:8:436-43.

5. Roos WP, Kaina B. DNA damage-induced cell death: from specific DNA lesions to the DNA damage response and apoptosis. Cancer Lett. 2013;332:237-48.

6. Guo R, Wang T, Shen H, Ge HM, Sun J, Huang ZH, Shu YQ. Involvement of mTOR and survivin inhibition in tamoxifen-induced apoptosis in human hepatoblastoma cell line HepG2, Biomedicine \& pharmacotherapy = Biomedecine \& pharmacotherapie. 2010;64:249-53.

7. Valente AJ, Graves DT, Vialle-Valentin CE, Delgado R, Schwartz CJ. Purification of a monocyte chemotactic factor secreted by nonhuman primate vascular cells in culture. Biochemistry. 1988;27:4162-8.

8. Yoshimura T, Robinson EA, Tanaka S, Appella E, Kuratsu J, Leonard EJ. Purification and amino acid analysis of two human glioma-derived monocyte chemoattractants. J Exp Med. 1989;169:1449-59.

9. Lin SJ, Yang DR, Li G, Chang C. TR4 nuclear receptor different roles in prostate cancer progression. Front Endocrinol (Lausanne). 2015;6:78.

10. Zhang J, Lu Y, Pienta KJ. Multiple roles of chemokine (C-C motif) ligand 2 in promoting prostate cancer growth. J Natl Cancer Inst. 2010;102:522-8.

11. Wang WQ, Liu L, Sun HC, Fu YL, Xu HX, Chai ZT, Zhang QB, Kong LQ, Zhu $X D$, Lu L, et al. Tanshinone IIA inhibits metastasis after palliative resection of hepatocellular carcinoma and prolongs survival in part via vascular normalization. J Hematol Oncol. 2012;5:69.

12. Wu CY, Yang YH, Lin YY, Kuan FC, Lin YS, Lin WY, Tsai MY, Yang JJ, Cheng YC, Shu LH, et al. Anti-cancer effect of danshen and dihydroisotanshinone I on prostate cancer: targeting the crosstalk between macrophages and 
cancer cells via inhibition of the STAT3/CCL2 signaling pathway. Oncotarget. 2017:8:40246-63.

13. Lin TH, Izumi K, Lee SO, Lin WJ, Yeh S, Chang C. Anti-androgen receptor ASC-J9 versus anti-androgens MDV3100 (enzalutamide) or Casodex (Bicalutamide) leads to opposite effects on prostate cancer metastasis via differential modulation of macrophage infiltration and STAT3-CCL2 signaling. Cell Death Dis. 2013;4:e764.

14. Izumi K, Fang LY, Mizokami A, Namiki M, Li L, Lin WJ, Chang C. Targeting the androgen receptor with siRNA promotes prostate cancer metastasis through enhanced macrophage recruitment via CCL2/CCR2-induced STAT3 activation. EMBO Mol Med. 2013;5:1383-401.

15. Tsao CK, Cutting E, Martin J, Oh WK. The role of cabazitaxel in the treatment of metastatic castration-resistant prostate cancer. Ther Adv Urol. 2014;6:97-104.

16. Ide H, Hatake K, Terado Y, Tsukino H, Okegawa T, Nutahara K, Higashihara E, Horie S. Serum level of macrophage colony-stimulating factor is increased in prostate cancer patients with bone metastasis. Hum Cell. 2008;21:1-6.

17. Mizutani K, Sud S, McGregor NA, Martinovski G, Rice BT, Craig MJ, Varsos ZS, Roca H, Pienta KJ. The chemokine CCL2 increases prostate tumor growth and bone metastasis through macrophage and osteoclast recruitment. Neoplasia. 2009;11:1235-42.

18. Loberg RD, Ying C, Craig M, Yan L, Snyder LA, Pienta KJ. CCL2 as an important mediator of prostate cancer growth in vivo through the regulation of macrophage infiltration. Neoplasia. 2007;9:556-62.

19. Lindholm PF, Sivapurapu N, Jovanovic B, Kajdacsy-Balla A. Monocyteinduced prostate cancer cell invasion is mediated by chemokine ligand 2 and nuclear factor-kappaB activity. J Clin Cell Immunol. 2015;6

20. Ito $\mathrm{Y}$, Ishiguro $\mathrm{H}$, Kobayashi $\mathrm{N}$, Hasumi $\mathrm{H}$, Watanabe $\mathrm{M}$, Yao M, Uemura $\mathrm{H}$. Adipocyte-derived monocyte chemotactic protein-1 (MCP-1) promotes prostate cancer progression through the induction of MMP-2 activity. Prostate. 2015;75:1009-19.

21. Araki S, Omori Y, Lyn D, Singh RK, Meinbach DM, Sandman Y, Lokeshwar VB, Lokeshwar BL. Interleukin-8 is a molecular determinant of androgen independence and progression in prostate cancer. Cancer Res. 2007;67:6854-62.

22. Wu CY, Cherng JY, Yang YH, Lin CL, Kuan FC, Lin YY, Lin YS, Shu LH, Cheng YC, Liu HT, et al. Danshen improves survival of patients with advanced lung cancer and targeting the relationship between macrophages and lung cancer cells. Oncotarget. 2017;

23. Gong Y, Li Y, Lu Y, Li L, Abdolmaleky H, Blackburn GL, Zhou JR. Bioactive tanshinones in salvia miltiorrhiza inhibit the growth of prostate cancer cells in vitro and in mice. Int J Cancer J Int du cancer. 2011;129:1042-52.

24. Shin DS, Kim HN, Shin KD, Yoon YJ, Kim SJ, Han DC, Kwon BM. Cryptotanshinone inhibits constitutive signal transducer and activator of transcription 3 function through blocking the dimerization in DU145 prostate cancer cells. Cancer Res. 2009;69:193-202.

25. Liu C, Li J, Wang L, Wu F, Huang L, Xu Y, Ye J, Xiao B, Meng F, Chen S, Yang $M$. Analysis of tanshinone IIA induced cellular apoptosis in leukemia cells by genome-wide expression profiling. BMC Complement Altern Med. 2012;12:5.

26. Zhang $Y$, Wei RX, Zhu XB, Cai L, Jin W, Hu H. Tanshinone IIA induces apoptosis and inhibits the proliferation, migration, and invasion of the osteosarcoma MG-63 cell line in vitro. Anti-Cancer Drugs. 2012;23:212-9.

27. Su CC. Tanshinone IIA decreases the migratory ability of AGS cells by decreasing the protein expression of matrix metalloproteinases, nuclear factor kappaB-p65 and cyclooxygenase-2. Mol Med Rep. 2016;13:1263-8.

28. Chuang MT, Ho FM, Wu CC, Zhuang SY, Lin SY, Suk FM, Liang YC. 15,16Dihydrotanshinone I, a compound of salvia miltiorrhiza Bunge, Induces Apoptosis through Inducing Endoplasmic Reticular Stress in Human Prostate Carcinoma Cells. eCAM. 2011:2011:865435.

29. Pollard JW. Trophic macrophages in development and disease. Nat Rev Immunol. 2009;9:259-70.

30. Peng L, Shu S, Krauss JC. Monocyte chemoattractant protein inhibits the generation of tumor-reactive T cells. Cancer Res. 1997;57:4849-54.

31. Zhuang S, Cheng TH, Shih NL, Liu JC, Chen JJ, Hong HJ, Chan P. Tanshinone IIA induces Heme oxygenase 1 expression and inhibits cyclic strain-induced interleukin 8 expression in vascular endothelial cells. Am J Chin Med. 2016;44:377-88.

32. Lee CY, Sher HF, Chen HW, Liu CC, Chen CH, Lin CS, Yang PC, Tsay HS, Chen JJ. Anticancer effects of tanshinone I in human non-small cell lung cancer. Mol Cancer Ther. 2008;7:3527-38.

33. Wilson C, Maxwell PJ, Longley DB, Wilson RH, Johnston PG, Waugh DJ. Constitutive and treatment-induced CXCL8-signalling selectively modulates the efficacy of anti-metabolite therapeutics in metastatic prostate cancer. PLoS One. 2012;7:e36545.
34. Wang $\mathrm{X}$, Yeung JH. Inhibitory effect of tanshinones on rat CYP3A2 and CYP2C11 activity and its structure-activity relationship. Fitoterapia. 2011;82:539-45.

35. Zabkiewicz J, Clarke AR. DNA damage-induced apoptosis: insights from the mouse. Biochim Biophys Acta. 2004;1705:17-25.

36. Zhang Z, Zhang J, Jin L, Song T, Wu G, Gao J. Tanshinone IIA interacts with DNA by minor groove-binding. Biol Pharm Bull. 2008;31:2342-5.

37. Ding L, Wang S, Qu X, Wang J. Tanshinone IIA sensitizes oral squamous cell carcinoma to radiation due to an enhanced autophagy. Environ Toxicol Pharmacol. 2016:46:264-9.

38. Fahmy O, Khairul-Asri MG, Hadi S, Gakis G, Stenzl A. The role of radical prostatectomy and radiotherapy in treatment of locally advanced prostate cancer: a systematic review and meta-analysis. Urol Int. 2017;

39. Gabka CJ, Benhaim P, Mathes SJ, Scheuenstuhl H, Chan A, Fu KK, Hunt TK. An experimental model to determine the effect of irradiated tissue on neutrophil function. Plast Reconstr Surg. 1995;96:1676-88.

40. Sowerby RJ, Gani J, Yim H, Radomski SB, Catton C. Long-term complications in men who have early or late radiotherapy after radical prostatectomy. Can Urol Assoc J. 2014;8:253-8.

41. Yarney J, Donkor A, Opoku SY, Yarney L, Agyeman-Duah I, Abakah AC, Asampong E. Characteristics of users and implications for the use of complementary and alternative medicine in Ghanaian cancer patients undergoing radiotherapy and chemotherapy: a cross- sectional study. BMC Complement Altern Med. 2013;13:16.

42. Nissen $\mathrm{N}$, Lunde A, Pedersen CG, Johannessen $\mathrm{H}$. The use of complementary and alternative medicine after the completion of hospital treatment for colorectal cancer: findings from a questionnaire study in Denmark. BMC Complement Altern Med. 2014;14:388.

43. Dhanoa A, Yong TL, Yeap SJ, Lee IS, Singh VA. Complementary and alternative medicine use amongst Malaysian orthopaedic oncology patients. BMC Complement Altern Med. 2014;14:404.

44. Du S, Yao Q, Tan P, Xie G, Ren C, Sun Q, Zhang X, Zheng R, Yang K, Yuan Y, Yuan Q. Protective effect of tanshinone IIA against radiation-induced ototoxicity in HEl-OC1 cells. Oncol Lett. 2013;6:901-6.

45. Zhang W, Li Y, Li R, Wang Y, Zhu M, Wang B, Li Y, Li D, Xie P, Liu B. Sodium Tanshinone IIA sulfonate prevents radiation-induced toxicity in $\mathrm{H} 9 \mathrm{c} 2$ cardiomyocytes. eCAM. 2017;2017:4537974.

\section{Submit your next manuscript to BioMed Central and we will help you at every step:}

- We accept pre-submission inquiries

- Our selector tool helps you to find the most relevant journal

- We provide round the clock customer support

- Convenient online submission

- Thorough peer review

- Inclusion in PubMed and all major indexing services

- Maximum visibility for your research

Submit your manuscript at www.biomedcentral.com/submit
( Biomed Central 